\title{
Exu, o andrógino canibal: aproximações entre mitologia e imaginário antropófago brasileiro para pensar alteridade
}

\author{
Exu, the androgynous canibal: approximations between mythology and \\ anthropophagous brazilian imaginary to think otherness
}

Florence Dravet

Universidade Católica de Brasília

$<$ flormd@gmail.com>

\section{Como citar este artigo (How to cite this article):}

DRAVET, Florence. Exu, o andrógino canibal: aproximações entre mitologia e imaginário antropófago brasileiro para pensar alteridade. Revista Famecos, Porto Alegre, v. 25, n. 2, p. 1-14, maio, junho, julho e agosto de 2018 : ID27839. DOI: http://dx.doi.org/10.15448/1980-3729.2018.2.27839.

\section{RESUMO}

O presente artigo propõe explorar o mito de Exu e o imaginário antropófago brasileiro em suas concepções indígenas a fim de extrair uma proposta epistemológica para a comunicação que parta de uma metafísica canibal afro-brasileira. Após estudarmos o mito de "Exu come tudo", e a interpretação indígena do fenômeno da antropofagia, fazemos uma releitura do Manifesto Antropófago modernista e, por aproximação, o atualizamos na mitologia afrobrasileira. Ao abordar essa realidade pelo viés do mito e do imaginário, propomos ultrapassar as barreiras das representações ocidentais em torno da antropofagia e contribuir para uma compreensão desta noção como a de um trajeto digestivo que permite construirse através do outro. Desta forma, concluímos que o mito de Exu, enquanto andrógino canibal, pode permitir expressar as bases de uma episteme comunicacional própria, brasileira e contemporânea.

\begin{abstract}
This article proposes to explore the myth of Exu and the Brazilian anthropophagous imaginary in its indigenous conceptions in order to extract an epistemological proposal for the communication that starts from an Afro - Brazilian cannibal metaphysics. After studying the myth of "Exu eats everything" and the indigenous interpretation of the phenomenon of anthropophagy, we re-read the Modernist Anthropophagic Manifesto and, by approximation, we update it in Afro-Brazilian mythology. In approaching this reality through the bias of myth and imaginary, we propose to overcome the barriers of the western representations around the anthropophagy and to contribute to an understanding of this notion as of a digestive path that allows to be constructed through the other. In this way, we conclude that the myth of Exu, as androgynous cannibal, can allow to express the bases of a communicational episteme, Brazilian and contemporary.
\end{abstract}


Onde os homens podem ser deuses, os animais podem ser homens.

(Mia Couto)

\section{Quando o vento virar - Introdução}

Para compreender a antropofagia, é preciso descolonizar o pensamento. O que queremos propor aqui é uma inversão nos termos da sentença acima: é preciso compreender a antropofagia para descolonizar o pensamento. Mas isso só será possível com o lento consumar da virada antropológica que ora se vislumbra nas ciências humanas brasileiras. Quem sabe, então, seja possível atualizar também a proposta modernista da antropofagia cultural e enfrentar um certo mal-estar na civilização'? Propomos aqui fazer uma leitura do mito de "Exu come tudo" à luz da noção antropológica de antropofagia, mas também, da noção filosófico-artística de antropofagia cultural ${ }^{2}$ que implica um pensamento capaz de ser tão andrógino quanto o próprio Exu.

Depois de ter reduzido os chamados "outros" a ficções oriundas de sua imaginação, a Antropologia põe-se à difícil tarefa de rever suas teorias e práticas a fim de pensar outramente. "Penser autrement" dizia Foucault (2011), pensar outramente, ou, ainda, pensar outra mente, com outra mente, segundo Viveiros de Castro (2015) pode nos permitir repensar as noções de identidade e de alteridade, através dos mitos indígenas, de seus ritos, seus discursos e suas próprias teorias antropológicas (porque de fato eles as têm). Esta é uma das propostas de alguns antropólogos contemporâneos e, especialmente, no Brasil, de Eduardo Viveiros de Castro (2015). Em seu livro "Metafísicas canibais", ele estabelece uma necessária relação entre Antropologia e Filosofia, chegando a propor uma metafísica que embasa toda a praxis indígena amazônica; metafísica esta, fundada na antropofagia e em uma concepção de humanidade que ele qualifica de "perspectivista" $\mathrm{e}$ "multinaturalista".

Certos de que a descolonização do pensamento é tarefa urgente, não só para o Brasil, mas para a Antropologia e para todos os saberes que dialogam com ela - incluindo neles a Comunicação enquanto campo cruzado de saberes exploramos e revisitamos a noção de "epistemologias do sul" (Santos, 2009) que

1 Embora não queiramos nos referir exatamente ao mal-estar freudiano (2011), que seria o de uma natureza constrangida pela cultura e pela vida social e de um consequente sentimento de frustração e infelicidade, reconhecemos um mal-estar que necessita ser repensado, à luz da própria revisão antropológica da noção de antropofagia e da metafísica nela implicada.

2 Pensamos não só no modernista Manifesto antropófago e na obra subsequente de Oswald de Andrade, mas também no seu legado posterior na música brasileira, notadamente no Tropicalismo, e no teatro, especialmente aquele proposto por José Celso Martinez Correia e o Teatro Oficina. Vale salientar que este último tem sido o expoente de uma vivência artístico-filosófica da figura de Exu. 3 Para um entendimento detalhado desses termos, ler Viveiros de Castro, E. Metafísicas Canibais, 2015, capítulos 2 e 3. 
entendemos, do ponto de vista do imaginário, como um sul não geográfico, a parte maldita do mundo, a noite, o desconhecido, o abjeto, o lugar dos saberes que foram historicamente relegados às margens, à excentricidade, reduzidos a uma inexpressividade insustentável que se deflagra no grito, na revolta e na crise histérica . O lugar, portanto, também, dos saberes que, inevitavelmente, retornam (Maffesoli, 2012). Os saberes digestivos antropófagos certamente se incluem aí.

A respeito desses saberes, o filósofo alemão contemporâneo Peter Sloterdijk, chamou de "empiria negra" ao conjunto dos objetos revelados pela lente daqueles que levantam suspeitas sobre o conhecido. A empiria negra é "secreta, polêmica, anárquica e dirigida para o terrível" e consiste em um "esclarecimento do esclarecimento que usa lentes desconfiadas" (Sloterdijk, 2012, p. 452). Perigoso desafio que, no mínimo, nos tira todos da nossa confortável zona de certeza. "Penso, logo existo"? Talvez, mas então haverei de saber pensar também os objetos abjetos e o impensável.

Mais que isso, já tratamos, em conclusões de pesquisa sobre o feminino e a pombagira no Brasil, da necessidade de reconhecer - e levar a sério metafísicas outras:

Talvez seja importante lembrar que a metafísica que se impõe ao Ocidente [esse lugar imaginário] não é exclusiva e que existe uma concepção de mundo e de comunicação, intensamente vivida no Brasil, que se vale de outra metafísica, de outra relação com os mundos divinos e espirituais, de outra organização socioantropológica de suas relações com o sagrado (Dravet e outros, 2016, p. 110).

\section{"Exu come tudo" - o antropófago}

Este é um dos mitos mais conhecidos de Exu, que transcrevo da coletânea de Reginaldo Prandi, embora possua várias versões. É nesta narrativa que se assenta o preceito, compartilhado por todas as vertentes afro-brasileiras, segundo o qual Exu (também conhecido como Legbara ou Elegbara, Eleguá, Bambogira etc.) ${ }^{4}$ deve sempre "comer primeiro", "ser lembrado" antes de qualquer oferenda ou ato ritualístico. Explicaremos o significado do preceito mais adiante. Por ora, segue-se a transcrição do mito:

Exu come tudo e ganha o privilégio de comer primeiro

Exu era filho de lemanjá e Orunmilá, irmão de Ogum, Xangô e Oxóssi. Exu comia de tudo e sua fome era incontrolável. Comeu todos os

4 É preciso lembrar aqui que as denominações para essa entidade, que atravessa a África e se dissemina no Brasil, no Caribe e na costa sul dos Estados Unidos, são numerosas e atendem não só a variações na qualidade e no atributo do Orixá, como a variações linguísticas de acordo com a região e o povo. 
animais da aldeia em que vivia. Comeu os de quatro pés e comeu os de pena. Comeu os cereais, as frutas, os inhames, as pimentas. Bebeu toda a cerveja, toda a aguardente, todo o vinho. Ingeriu todo o azeite de dendê, todos os obis 5 . Quanto mais comia, mais fome Exu sentia. Primeiro, comeu tudo o que mais gostava, depois, começou a devorar as árvores, os pastos, e já ameaçava engolir o mar. Furioso, Orunmilá compreendeu que Exu não pararia e acabaria por comer até mesmo o céu. Orunmilá pediu a Ogum que detivesse o irmão a todo custo. Para preservar a Terra e os seres humanos e os próprios Orixás, Ogum teve que matar o próprio irmão.

A morte, entretanto, não aplacou a fome de Exu. Mesmo depois de morto, podia-se sentir sua presença devoradora, sua fome sem tamanho. Os pastos, os mares, os poucos animais que restavam, todas as colheitas, até os peixes iam sendo consumidos. Os homens não tinham mais o que comer e todos os habitantes da aldeia adoeceram e de fome, um a um, foram morrendo. Um sacerdote da aldeia consultou o oráculo de Ifá e alertou Orunmilá quanto ao maior dos riscos: Exu, mesmo em espírito, estava pedindo sua atenção. Era preciso aplacar a fome de Exu. Exu queria comer. Orunmilá obedeceu ao oráculo e ordenou: "Doravante, para que Exu não provoque mais catástrofes, sempre que fizerem oferendas aos Orixás, deverão em primeiro lugar servir comida a ele". Para haver paz e tranquilidade entre os homens, é preciso dar de comer a Exu, em primeiro lugar (Prandi, 2001, p. 45-46).

Uma variação do mesmo mito, apresentada por Juana Elbein dos Santos e Descoredes Maximiliano dos Santos (2014), narra que foi quando Exu engoliu a própria mãe, lemanjá, e se preparava para também comer seu pai, que este, horrorizado, o cortou ao meio. Porém, de nada adiantou porque nasceram dois Exus e Orunmilá teve que cortar os dois ao meio, que também retomaram vida, passando então a existir quatro Exus e assim, sucessivamente, até que se formaram 201 Exus espalhados pelo mundo, devorando tudo. Nesse mito, os autores também terminam narrando que, quando Orunmilá decretou o preceito, Exu ficou satisfeito e regurgitou tudo o que havia comido, devolvendo a vida sobre a terra. Este fim sobre a regurgitação é, veremos, de suma importância.

Em primeiro lugar, para entender o mito, é preciso saber que na concepção nagô (como, aliás, na concepção indígena amazônica, segundo Viveiros de (astro), os corpos são diversos por natureza, mas a alma é universal. Portanto, todos os seres são dotados de espírito (o que não se questiona) e o importante passa a ser conhecer a natureza do corpo físico dos seres, a fim de determinar se estes são humanos ou divinos. Na concepção judaico-cristã é exatamente o inverso: é preciso determinar se um corpo possui uma alma para considerá-

5 Noz de cola, muito usada na ritualística das religiões afrobrasileiras. 
lo humano. Podemos dizer, na esteira de Lévi-Strauss, que a questão do humano/não-humano põe-se de maneira fundamentalmente distinta segundo a concepção judaico-cristã ou indígena, ou ainda banto e nagô. Nesse caso, melhor seria tratar de concepção afro-indígena, algo que podemos entender como a origem do que tomamos aqui como cultura afro-brasileira ${ }^{6}$ antropófaga. No livro Race et histoire, Lévi-Strauss reportava que:

Nas Antilhas, alguns anos após o descobrimento da América, enquanto os espanhóis despachavam comissões de inquérito para saber se os indígenas possuíam alma ou não, estes tratavam de submergir prisioneiros brancos, para verificar, com base numa longa e cuidadosa observação, se seus cadáveres apodreciam ou não (LéviStrauss, 2007, p. 17, tradução nossa) ${ }^{7}$.

Entre os bantos e os nagôs, tanto quanto os indígenas amazônicos, todos os seres dotados de corpo físico são potencialmente humanos. Apenas os deuses são distintos, mas então é preciso estabelecer um sistema de comunicação efetivo entre humanos e deuses, que garanta a harmonia entre eles. É precisamente disso que o mito de Exu trata: como fazer para que, uma vez criado o mundo manifesto, ele não seja destruído e que deuses e homens vivam em harmonia? A resposta é dada pelo mito e pode ser considerada, como a própria Comunicação, esse ato de vinculação e afinização (Baitello Jr, 2005).

Ao comer todos os seres, Exu - o filho manifesto sobre a Terra - imprimeIhes sua qualidade divina, ele os aproxima de si, de sua natureza, de sua interioridade divina e com a regurgitação, da força que Ihe sai pela boca. Os seres, enquanto corpos, tornam-se humanos pelo fato de serem marcados pelo divino, de serem dotados dessa alma comum que Exu Ihes atribui com seu ato devorador. Sendo assim, ao devorar os seres, Exu lhes dá, em realidade, a possibilidade da vida harmônica com a esfera divina. É dizer que antes de Exu, a vida na Terra seria inviável para os seres então desconectados da divindade. A vida, portanto, só é viável se for relacional (divino/humano e corpo/alma ou ainda cultura/natureza). E o que relaciona os seres entre si e com o divino é, propriamente, o sistema digestivo. Nesse sentido, Exu é aquele que permite o

6 O uso do termo afro-brasileira para a cultura brasileira negra, cujas raízes africanas remontam aos tempos da escravidão e passaram por um longo processo de transformações, já é consagrado. Mas é preciso dizer que a cultura dita afro-brasileira é também indígena. A ponto de nos perguntarmos a pertinência do termo. Parece-nos que há um terreno fértil para a reflexão aí: Indígena? Afro-brasileira? Afro-indígena? Ou, simplesmente, brasileira? Optamos aqui pelo encontro das culturas afro-indígenas. 7 Texto original: "Dans les Grandes Antilles, quelques années après la découverte de l'Amérique, pendant que les Espagnols envoyaient des commissions d'enquête pour rechercher si les indigènes avaient ou non une âme, ces derniers s'employaient à immerger des blancs prisonniers afin de vérifier par une surveillance prolongée si leur cadavre était, ou non, sujet à putréfaction" (2007, p.17). 
trânsito entre o dentro e o fora, o fora e o dentro; o comunicador de uma força vital, dinâmica e relacional, também transformadora.

Todavia, a ação de Exu tem um custo: é preciso Ihe dar de comer. Dito de outro modo, é preciso retribuir a Exu a sua dádiva, reconhecê-la, dando-lhe de comer todas as vezes que se queira entrar em relação com qualquer outra esfera divina ${ }^{8}$. Isto posto, o que nos interessa entender aqui é a relação entre esse mito e o fenômeno antropofágico, na etnografia indígena e na cultura afro-brasileira.

\title{
Antropologia da predação
}

Uma aproximação pode ser feita entre o ato de devorar no mito de Exu e o de guerrear/caçar seguido do ato ritualístico de comer o inimigo (no caso dos prisioneiros de guerra) ou do ato de alimentar-se (no caso da presa de caça). Essa relação corresponde ao que Lévi-Strauss (2000) chamou, ao se referir aos trabalhos etnográficos brasileiros, de "Metafísica da predação", que Viveiros de Castro (2015) desenvolve como uma pista para pensar "metafísicas canibais" e que optamos por chamar aqui, uma vez que não somos antropólogos e que nos atemos aos mitos e sua atualização em terreiros afro-brasileiros, de "Imaginário antropófago".

Os traços gerais do canibalismo entre os Tupinambá que habitavam a costa brasileira do século XVI são lembrados por Viveiros de Castro nos seguintes termos:

\begin{abstract}
Tratava-se de um elaborado sistema de captura, execução e devoração cerimonial de inimigos. Os cativos de guerra, frequentemente tomados de povos de mesma língua e costumes que a dos captores, podiam viver bastante tempo junto a estes, antes da morte na praça central da aldeia. Eles eram em geral bem tratados, vivendo em liberdade vigiada, enquanto se faziam os longos preparativos para o grande rito de execução (Viveiros de Castro, 2015, p. 157) .
\end{abstract}

Duas questões se colocam a respeito dessa prática: a da interação dos humanos com os deuses e o mundo dos mortos e a dos humanos entre si. No fundo, essas duas interações são ambas relações de alteridade. A primeira é radical (o outro divino), a segunda é relativa (o outro humano). Não se sabe se o envolvimento de entidades incorpóreas (deuses ou espíritos mortos) nos atos ritualísticos canibais sempre tinham finalidade propiciatória (qual seja, de colocá-

8 Desenvolvemos essa interpretação de Exu no artigo Corpo, linguagem e real: o sopro de Exu Bará e seu lugar na comunicação Ilha do Desterro v. 68, n. 3, p. 015-025, Florianópolis, set/dez 2015.

9 A esse respeito, embora trate de um inimigo de grupo étnico-linguístico distinto, o filme de ficção brasileiro Como era gostoso meu francês de Nelson Pereira dos Santos (1973), baseado nos diários de Hans Staden, é um excelente documento. 
las a seu favor). Há várias teses sobre o assunto. Para Florestan Fernandes (1970), o sacrifício de um ser humano sempre se dirigia a uma entidade espiritual e tinha como finalidade a vingança dos mortos em guerra e a celebração pela execução e devoração em grupo do cativo inimigo. Já, Viveiros de Castro contesta a ideia que esta fosse a finalidade última. Para ele, podia haver entidades espirituais envolvidas, mas nem sempre a finalidade era a de propiciar vingança junto a esses seres e sim, de reforçar a identidade do grupo através do inimigo.

Segundo o autor, com a prática canibal de devoração do inimigo, a ser entendido como o outro, no sentido da alteridade, " $\mathrm{O}$ 'eu' se determina como 'outro' pelo ato mesmo de incorporar esse 'outro', que por sua vez se torna um 'eu', mas sempre no outro, através do outro (através também no sentido solecístico de 'por meio de')" (Viveiros de castro, 2015, p. 159).

Com isso, supõe-se que aquilo que no "outro" era devorado não era sua substância ou matéria, nem física, nem metafísica. Era a condição de inimigo, de alteridade, de diferença do corpo. Sendo assim, a devoração antropofágica tem por finalidade o estabelecimento de uma relação com a alteridade que serve de ponto de vista sobre o "eu": autodeterminação recíproca, uma vez que ser devorado em ato ritualístico é honroso se comparado com a devoração acidental por um animal selvagem, por exemplo. Como sabemos, o sistema tradicional da vingança é cíclico e obedece a uma lógica predatória.

A grande novidade trazida pela antropofagia indígena parece ser, portanto, essa maneira de apreender a si mesmo a partir e através do outro. Ora, a tradição antropológica do ponto de vista do ocidente foi majoritariamente a da apreensão do outro a partir de si mesmo, com a pretensão à objetividade e a relação sujeito/objeto que conhecemos bem. Mais que isso, foi a da volta a si mesmo: "À força de ver sempre o Mesmo no Outro - de dizer que sob a máscara do outro somos nós que estamos olhando para nós mesmos -, acabamos por tomar o atalho que nos leva ao que realmente, no fim e no fundo, nos interessa, a saber: nós mesmos." (Viveiros de Castro, 2015, p. 21).

Isso nos faz pensar numa crítica bastante frequente do senso comum brasileiro à sua própria prática cultural de identificação que consiste em considerar que o brasileiro se volta demais para os outros e pouco valoriza sua própria cultura. Não haveria, portanto, no imaginário antropófago, um tipo de sabedoria da autodeterminação pelo outro? Ou seja, um elemento a ser levado a sério nessa maneira aparentemente autodesvalorizante de se autovalorizar? Propomos uma incursão na proposta modernista da Antropofagia Cultural para pensarmos o assunto não mais em termos de antropofagia antropológica, mas de uma antropofagia simbólico-imaginária. 


\section{Antropofagia Cultural, aliança e devir-Exu}

"Meu hemisfério sul comeu meu hemisfério norte", diz José Celso Martinez Corrêa, em entrevista filmada (Palavra Encantada, 2008), ilustrando a ideia antropofágica dos modernistas que ele levou a cabo em sua proposta teatral com a Companhia Oficina. Um gesto de rebolado e um sorriso estampado no rosto acompanham sua fala. Por fim, ele gargalha. José Celso aplica em corpo e espírito dois trechos do Manifesto Antropófago, obra fundadora do movimento: "O espírito recusa-se a conceber o espírito sem o corpo. Antropomorfismo" e "A alegria é a prova dos nove". E aplica, sobretudo, sua ideia central: "Só me interessa o que não é meu. Lei do homem. Lei do Antropófago" (Andrade, 1976).

Com efeito, com o Manifesto Antropófago, datado do "Ano 374 da Deglutição do Bispo Sardinha", Oswald de Andrade lançava o mito da antropofagia e trazia o ritual canibal para as relações culturais internacionais.

A rigor, já não se trata nesse caso, do dualismo eu/outro, mas de um interesse [ser entre], de um entrelugar, de uma flecha desejante lançada em um movimento vertiginoso de perda irreversível de si. Trata-se de outrar-se, verbo cuja existência em nossa língua devemos a Bernardo Soares/Fernando Pessoa (Ferraz, 2015, p. 87).

O que nos interessa na interpretação proposta por Ferraz é a ideia desse "entrelugar", desse terceiro entre o eu e o outro, um terceiro que surge da implosão do eu no encontro com o outro. Um movimento de fora para dentro (comer o outro) que resulta num movimento de dentro para fora (outrar-se).

O movimento antropófago foi violentamente rejeitado e longamente ignorado durante quatro décadas, para voltar à cena dos debates sobre arte e cultura brasileira com o movimento Tropicália liderado por Caetano Veloso e Gilberto Gil nos anos 1960. Depois, foi novamente esquecido. No entanto, à hora dos debates internacionais sobre questões de acolhimento de migrantes que necessitam de asilo, à hora das crises políticas brasileiras, das tensões sociais internas e dos debates que engendram, como, por exemplo, o da corrupção como um mal social e o da violência brasileira, ou as oposições entre discursos e posturas anacronicamente homofóbicas por um lado e movimentos libertários LGBT por outro, pensar com a lógica do ventre parece ser um ideal ao mesmo tempo absurdo (de caráter quase surrealista) e, no entanto, senão salutar, ao menos alentador para quem tem fome de esperança. Voltemos, portanto, às epistemologias do sul eà proposta digestiva trazida pelo imaginário antropófago brasileiro.

Não se tratou apenas de uma proposta para a arte ou de uma justificativa poética para levantar a autoestima brasileira. Tampouco se trata de reação 
violenta a fenômenos como pós-colonialismo, globalização, etc. Trata-se de uma autorreflexão filosófica e política do Brasil a partir de sua arte, ou seja, de sua pulsão criativa, ou, dito de outro modo daquilo que Freud chamou de libido. Mas a cultura brasileira não é freudiana. Ela foi capaz de engolir Freud e regurgitar um Freud-Jabuti cujo mal-estar na civilização encontra seu relativo equilibro na alegria:

Antropofagia. Absorção do inimigo sacro. (...) O que se dá não é uma sublimação do instinto sexual. É a escala termométrica do instinto antropofágico. De carnal, ele se torna eletivo e cria a amizade. Afetivo, o amor. Especulativo, a ciência. Desvia-se e transfere-se. Chegamos ao aviltamento. A baixa antropofagia aglomerada nos pecados de catecismo - a inveja, a usura, a calúnia, o assassinato. Peste dos chamados povos cultos e cristianizados, é contra ela que estamos agindo. Antropófagos (Andrade, 1976, s. n.).

O saber antropófago adquire aqui um sentido que vale aproximar da relação com a alteridade sugerida por Viveiros de Castro (2015) em suas interpretações dos ritos canibais. Trata-se de uma forma de absorver a carne do outro (inimigo, cunhado, não-eu) para, através dela, se fortalecer e se reconhecer como um ser que só pode existir não só em relação a esse outro, mas através dele. Os atos de devoração, deglutição, absorção e rejeição do excesso são a forma da antropologia indígena, uma antropologia pela boca e pelo trajeto digestivo, que não resulta no reforço de si mesmo como um mesmo, mas na renovação ou reinvenção de si mesmo através do outro, com o outro agora fazendo parte do si mesmo. Viveiros de Castro (2015) aproxima essa concepção de ser e outrar-se com a do devir (Deleuze e Guatarri, 1995) em que transcendência e imanência passam a ser uma só em constante transformação, sem relação de filiação entre as coisas, mas com relações múltiplas de aliança, o terceiro incluído, fruto do processo da vingança: "Mas não foram cruzados que vieram. Foram fugitivos de uma civilização que estamos comendo, porque somos fortes e vingativos como o Jabuti1"', (Andrade, 1976). A noção de aliança é aqui fundamental, pois exime os seres da relação de filiação: passa a valer a aliança contra a natureza; o estabelecimento de uma aproximação; uma contiguidade; com isso, a diferença percebe-se de outra perspectiva, como algo necessário e cheio de potencial para ser e interessar-se pelo outro: outrar-se.

Assim, na antropologia africanista tanto quanto na americanista, há múltiplos exemplos de relações por aliança e contiguidade que permitem

10 O Jabuti é o animal que serve de referência a Oswald de Andrade em seu manifesto: "Somos fortes e vingativos como o Jabuti". Nativo da América do Sul, nas religiões indígenas representa a perseverança e a força. 
estabelecer novos tipos de vínculos entre categorias diversas de seres: humanos e animais, humanos e deuses se aliam intensamente, a ponto de já não se distinguirem em todos os planos. Vejamos os xamãs e seus devires-animais. Vejamos os feiticeiros e sacerdotes e as incorporações por deuses ou outras categorias de espíritos. Assim também os índios canibais e seus devires-inimigos. Assim também Exu. O Orixá da comunicação que ora podemos entender como o próprio devir, aquele que "come tudo". De certa forma, de acordo com essa concepção de alteridade como relação de aliança, todos os seres vivos possuem algum tipo de vínculo com Exu e, necessariamente, com as divindades com as quais ele os vincula.

\section{Exu, o canibal: alegria relacional e androginia}

Um dizer do universo afro-brasileiro afirma: "Exu é tudo e está em tudo". É que ele, ao nascer, comeu todos os seres vivos que encontrou no caminho. Em seguida, vomitou-os, preenchidos de seu emi, a força divina que sai pela boca, está na saliva, na baba, no sopro, no canto, na fala. Esse é o princípio da manifestação relacional e interdependente. Exu, enquanto manifestação dos dois princípios divinos, o masculino e o feminino (Filho de Orunmilá e Yemanjá), é o terceiro elemento, o elemento expansivo manifesto, ou, o filho. O número três, número de Exu (portador do tridente) pode, portanto, ser lido no sentido familiar porque cristão - da Trindade (Pai, Mãe, Filho). De fato, Exu é Bambogira, manifestação feminina (que possivelmente deu origem ao termo Pombagira), Orixá que se manifesta gargalhando e girando, princípio feminino da manifestação divina entre e dentro dos seres, cujo principal atributo manifesto é o da geração (o ventre). Mas Exu é também o dono do ogó, o falo sagrado cuja força fecundadora e criadora é animada pelo movimento dinâmico próprio a Exu. Por fim, Exu é a criança travessa - um ser próximo ao Saci Pererê - que toma a forma de um torvelinho, aparece nas encruzilhadas e se esconde nos bambuzais.

Outra interpretação do número três, não exclusiva da anterior, também nos informa sobre a qualidade de comunicador de Exu. Ele se apresenta como o próprio princípio do terceiro incluído entre os pares de opostos complementares (os polos feminino e masculino). Princípio de relação que admite a contradição e a não-contradição da realidade baseada em vários níveis: físico, metafísico, ontológico. Tal princípio se aproxima de uma noção de feminino como androginia que já apresentamos em trabalhos anteriores e que se faz presente, também, no Manifesto Antropófago.

Oswald de Andrade, no Manifesto utiliza o termo "matriarcado" numa referência à libertação do sujeito, em oposição ao patriarcado, este sim, governado por instituições de poder, castradoras e cheias de interditos: “Contra 
a realidade social, vestida e opressora, cadastrada por Freud - a realidade sem complexos, sem loucura, sem prostituições e sem penitenciárias do matriarcado de Pindorama" (Andrade, 1976, s/p). O "matriarcado de Pindorama" faz eco ao caráter trino de Exu, ao caráter unificador daquele que reúne em si o potencial das contradições, sem distinções, da realidade compreendida em seus múltiplos níveis, aquele que liberta dos sistemas de lei excludentes. A realidade do "matriarcado de Pindorama", assim como a concepção de mundo na perspectiva afro-brasileira de Exu, é aquilo que é e não é ao mesmo tempo. O enfrentamento da grande questão metafísica, agora deslocada para a problemática brasileira: "Tupi or not Tupi" transcende o caráter trágico da vida e convoca a alegria através do continuum movente do tudo e do nada: Exu.

Aquele que ora é algo, ora é outro algo. Homem-mulher-criança. Andrógino canibal que tudo devora e regurgita. Ele é o próprio princípio do terceiro incluído que permite abordar a realidade de um ponto de vista não logocêntrico, e sim feminino e compreensivo. Aqui, o termo feminino, que faz eco ao termo "matriarcado" empregado por Oswald de Andrade, não deve ser entendido em sua dimensão de diferença de gênero, e sim, em sua qualidade andrógina, no sentido daquilo que transcende os gêneros e se afirma como ideal de compreensão, sem distinção, um ideal considerado abjeto e muitas vezes repulsivo porque indefinido, pura potencialidade, húmus onde vigoram todas as sensações, impressões, todas as indefinições e imprecisões, todas as possibilidades ainda em estado de potência. Voltamos, mais uma vez, à noção de empiria negra anunciada no começo deste texto.

\section{Quando o vento virar - Conclusão}

O que propusemos com esse imaginário antropófago, foi um trajeto digestivo: degeneração/regeneração da episteme, para uma degeneração/ regeneração metafísica antropófaga. Se Oswald de Andrade afirmou: "Fizemos Cristo nascer na Bahia. Ou em Belém do Pará/ Mas nunca admitimos o nascimento da lógica entre nós" (Andrade, 1976, s. p.) é que ele necessitava se colocar contra o sistema dominante social, econômico, filosófico, epistemológico. O mito de Exu reflete a concepção oswaldiana, e a liberta dos embaraços das relações de poder ao dizer: "Exu mata o inimigo ontem, com a pedra que atirou hoje" e poderíamos acrescentar em consonância com o mito exposto acima: "e devora-o".

Aliança propiciada pelo sistema digestivo. Diversidade como riqueza. Acolhimento feminino. Compreensão no receptáculo do ventre-cabaça. Ingestão/expulsão. Movimento contínuo. Vida relacional. Terceiro incluído e terceiro oculto. Percepção deleuziana da vida como devir, Exu é o deus brasileiro 
mais arcaico, mas também o mais contemporâneo em termos epistemológicos, capaz de reunir em si ciência, filosofia e sacralidade, o Orixá da manifestação é tanto atualização como potencialização.

A manifestação de um fenômeno qualquer é equivalente a uma certa atualização, a uma tendência para a identidade, mas esta mesma manifestação implica uma contenção, uma potencialização de tudo o que esse fenômeno não é, em outras palavras, da não-identidade. A potencialização não é uma aniquilação, um desaparecimento, mas simplesmente uma espécie de memorização do ainda não manifestado. (...) A Realidade em sua integralidade não é senão uma perpétua oscilação entre a atualização e a potencialização. Não há atualização absoluta (Nicolescu, 2009, p. 2).

Ele veio da África e aportou ao Brasil nas condições que conhecemos. Nunca foi catequizado, embora tenha "engolido" Santo Antônio. Tudo indica que é o maior responsável pela conspiração que "fez Cristo renascer na Bahia". É provável que também tenha engolido a mata amazônica, tragado Peri e a sabedoria indígena, edesta forma, regenerado a episteme. Exu, quando deixarmos o vento virar, ainda dará muito que pensar à nossa área, na encruzilhada dos saberes. Pois ele permite pensar a mídia, o médium, a mediação, o corpo e a incorporação em todos os seus sentidos, as contradições e as não-contradições, os interesses, os indivíduos e os partícipes, a complexidade, as identidades e as não-identidades, as comunidades e o comum. A respeito da mídia em específico, lembramos aqui, em consonância com nossa proposta, do trabalho de Norval Baitello Jr. (2005) que propõe uma iconofagia midiática, ou seja um trajeto midiático em que as imagens vão devorando a si mesmas a ponto de se tornarem produtoras inflacionárias de imagens que nunca satisfazem a sua própria sede de consumação de imagens. Assim, é possível postular uma dívida entre Exu e a mídia e seu processo autodevorador. Por isso, afirmamos que Exu é agente produtor de um imaginário antropófago que necessita se regenerar. Enquanto ser andrógino e canibal é, também, o Orixá da regeneração epistemológica dos saberes do sul. Uma discussão ainda em aberto.

\section{REFERÊNCIAS}

ANDRADE, Oswald de. Manifesto antropófago. In: TELES, G. M. Vanguarda européia e modernismo brasileiro: apresentação e crítica dos principais manifestos vanguardistas. Petrópolis: Vozes; Brasília: INL, 1976. Disponível em: http://www. ufrgs.br/cdrom/oandrade/oandrade.pdf. Acesso em: 25 jun. 2017. 
BAITELLO Jr, N. A era da iconofagia. Ensaio de comunicação e cultura. São Paulo: Hacker editores, 2005.

COMO era gostoso o meu francês. Direção: Nelson Pereira dos Santos, Roteiro: Nelson Pereira dos Santos, Humberto Mauro, Elenco: Ana Maria Magalhães, Arduíno Colassanti, Eduardo Imbassahy Filho e José Kléber. Produção: Condor Filmes; Produções Cinematográficas L. C. Barreto Ltda. Nova lorque: 1973.

DELEUZE, G. GUATARRI, F. Mil platôs. Capitalismo e esquizofrenia. São Paulo: Editora 34, 1995.

DRAVET, F. Corpo, linguagem e real: o sopro de Exu Bará e seu lugar na comunicação. Ilha do Desterro v. 68, n. 3, p. 15-25, Florianópolis, set./dez. 2015. http://dx.doi.org/10.5007/2175-8026.2015v68n3p15.

DRAVET e outros. Pombagira. Encantamentos e abjeções. Brasília: Casa das Musas, 2016.

FERNANDES, F. A função social da guerra na sociedade Tupinambá. São Paulo: Pioneira/Edusp, 1970.

FERRAZ, M. C. F. Ruminações. Cultura letrada e dispersão hiperconectada. Rio de Janeiro: Garamond, 2015.

FOUCAULT, M. As palavras e as coisas. Uma arqueologia das ciências humanas. São Paulo: Martins Fontes, 2011.

FREUD, S. O mal-estar na civilização. São Paulo: Penguin e Companhia das Letras, 2011.

LEVI-STRAUSS, C. Postface, L'Homme, Paris, n. 154-155, p. 713-720, abr. set. 2000. Disponível em: http://lhomme.revues.org/57 Acesso em: 31 jan. 2017.

C. Race et histoire. Paris : Gallimard, 2007.

MAFFESOLI, M. O tempo retorna. Formas elementares da pós-modernidade. Rio de Janeiro: Forense Universitária, 2012.

NICOLESCU, B. Contradição, lógica do terceiro incluído e níveis de realidade, tradução de conferência proferida em 2009. Disponível em: www.cetrans.com. br. Acesso em: 20 jan. 2017.

PALAVRA (en)cantada. Direção e Roteiro: Helena Solberg. Produção: David Meyer. Brasil, Rio de Janeiro: Biscoito fino, 2008. 86 min.

PRANDI, R. Mitologia dos orixás. São Paulo: Companhia das Letras, 2001.

SANTOS, B. S. e MENESES, M. P. Epistemologias do Sul. Coimbra: Almedina, 2009. 
SANTOS, J. E. e SANTOS, D. M. (Mestre Didi Asipa). Èxú. Salvador: Corrupio, 2014.

SLOTERDIJK, P. Crítica da razão cínica. São Paulo: Estação Liberdade, 2012.

VIVEIROS DE CASTRO, E. Metafísicas canibais. São Paulo: Cosac Naify, 2015.

Recebido em: 29/6/2017

Aceito em: 31/7/2017

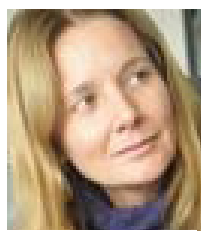

Dados da autora:

Florence Dravet | flormd@gmail.com

Docente no Programa de Pós-graduação em Comunicação da Universidade Católica de Brasília. É doutora em Didactologia das Línguas e Culturas, com tese em Comunicação Intercultural, na Universidade de Paris III - Sorbonne-Nouvelle. Programa de Pós-graduação em Comunicação, Universidade Católica de Brasília.

Endereço da autora:

SGAN 916 W5 Norte, Campus II - Asa Norte.

Brasília (DF) - Brasil 